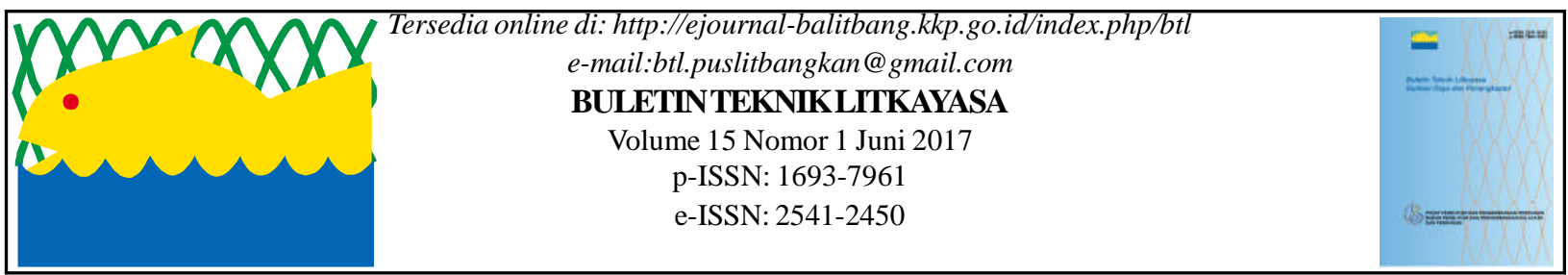

\title{
TEKNIK ANALISIS DATA PARAMETER FISIKA KIMIA AIR DI SUNGAI KAMPAR KANAN, PROPINSI RIAU MENGGUNAKAN WATER QUALITY INDEX
}

Puji Purnama dan Dyah Ika Kusumaningtyas

Teknisi Litkayasa pada Balai Penelitian Pemulihan dan Konservasi Sumber Daya Ikan Teregistrasi I tanggal: 06 Maret 2017; Diterima setelah perbaikan tanggal: 08 Juni 2017; Disetujui terbit tanggal: 13 Juni 2017

\section{PENDAHULUAN}

Sungai Kampar terletak di kabupaten Kampar, Propinsi Riau. Sungai Kampar mempunyai panjang \pm $413,5 \mathrm{~km}$ dengan kedalam rata-rata 7,7 meter dengan lebar rata-rata 143 meter (Angka, 2014). Sungai Kampar dan anak sungainya berperan sentral bagi masyarakat sekitar dan telah dimanfaatkan sepanjang sejarah peradaban di sekitar aliran sungai. Selain usaha penangkapan ikan, bertambahnya jumlah penduduk yang bermukim di bantaran sungai, industri, penebangan hutan, perluasaan lahan perkebunan, dan penambangan pasir telah mengakibatkan terjadinya pencemaran sungai (Fithra dan siregar, 2010).

Teknik analisis data diperlukan untuk mengetahui status mutu air di sungai Kampar kanan. Salah satu teknik analisis data fisika kimia air menggunakan metode water quality index (WQI). Water quality index (WQI) adalah salah satu alat untuk mengevaluasi tingkat pencemaran perairan yang cukup efektif dengan informasi yang komprehensif, mudah dipahami dan dapat digunakan oleh masyarakat (Bardalo et al, 2006; Alam \& Pathak, 2010). Metode analisa WQI dari beberapa parameter kualitas air dapat menjadi salah satu alat monitoring kualitas air. Nilai WQI berkisar dari 0 - 100 dengan kriteria nilai yang tinggi menunjukkan kualitas air yang lebih baik. (Bardalo et al, 2006; Alam \& Pathak, 2010). Penentuan (WQI) secara cepat menggunakan Water Quality Index Calculator (www.water-research.net). Tujuan dari penelitian ini adalah untuk memberikan informasi teknik analisa data dan hasil nya dalam penentuan status mutu air Sungai Kampar di Kabupaten Kampar, Propinsi Riau.

\section{POKOK DAN BAHASAN Waktu dan Tempat}

Penelitian ini dilakukan pada bulan Juli dan Oktober 2016 di bagian hulu, tengah, dan hilir Sungai Kampar Kanan, Kabupaten Kampar, Propinsi Riau. Peta lokasi penelitian dan letak geografis tertera pada Gambar 1 dan Tabel 1.

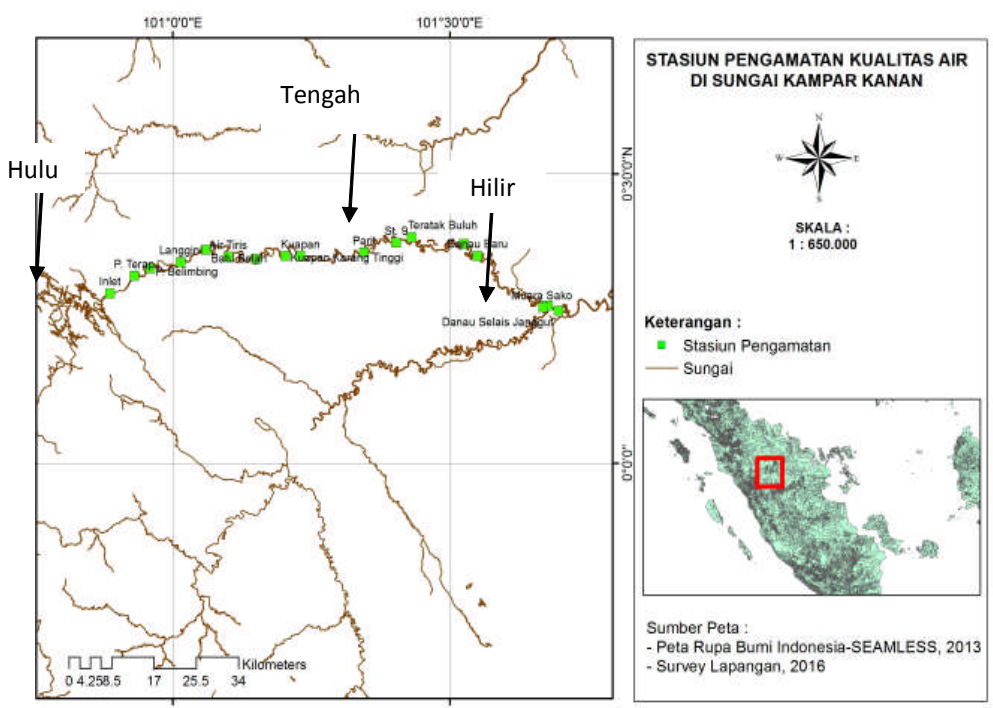

Gambar 1. Peta lokasi penelitian. 
Tabel 1. Letak geografis lokasi penelitian

\begin{tabular}{ccc}
\hline Stasiun penelitian & $\mathbf{N}$ & $\mathbf{E}$ \\
\hline Hulu sungai & $00^{\prime} 29.390^{\prime \prime}$ & $1000^{\prime} 88.721^{\prime \prime}$ \\
Tengah Sungai & $00^{\prime} 23.461^{\prime \prime}$ & $101^{\prime} 25.864^{\prime \prime}$ \\
Hilir sungai & $00^{\prime} 16.182^{\prime \prime}$ & $101^{\prime} 40.141^{\prime \prime}$ \\
\hline
\end{tabular}

\section{Prosedur Kerja}

a. Langkah-langkah teknik analisa data penentuan status mutu air menggunakan metode WQI:

- Menghitung nilai change in temp (temperatur selisih antara nilai pengukuran 1 dan 2, atau 2 dan 3 atau kalau banyak pengukurannya ambil rata-ratanya. (catatan waktu dan tempat harus sama)

- Merubah parameter yang satuannya masih berbeda antara satuan hasil pengukuran dengan satuan WQI_Calculator. Satuan yang digunakan dalam WQI disajikan dalam tabel 2 dan untuk DO jenuh disajikan pada Tabel 3.

- Memasukkan nilai parameter yang diukur baik insitu maupun eksitu kedalam kolom pada aplikasi WQI_calculator

Hasil total yang didapatkan dari pengukuran dengan aplikasi WQI_calculator diidentifikasi statusnya dengan melihat tingkat pencemaran. Nilai tingkat pencemaran menurut WQI tertera pada Tabel 4.

Tabel 2. Satuan yang digunakan dalam WQI

\begin{tabular}{llc}
\hline No & Parameter & Satuan \\
\hline 1 & DO & \%sat \\
2 & pH & Unit \\
3 & Suhu & ${ }^{\circ} \mathrm{C}$ \\
4 & Nitrat & $\mathrm{mg} / \mathrm{L}$ \\
5 & Kekeruhan & $\mathrm{NTU}$ \\
6 & total P & $\mathrm{mg} / \mathrm{L}$ \\
7 & konsentrasiE.coli & $\mathrm{CFU}$ \\
8 & konsentrasi fecal coliform & $\mathrm{CFU}$ \\
\hline
\end{tabular}

Sumber : www.water-research.net

Tabel 3. Hubungan antara oksigen terlarut jenuh dan Suhu pada tekanan udara $760 \mathrm{mmHg}$.

\begin{tabular}{cccccc}
\hline $\begin{array}{c}\text { Suhu } \\
\left({ }^{\circ} \mathbf{C}\right)\end{array}$ & $\begin{array}{c}\text { Kadar oksigen } \\
\text { terlarut }(\mathbf{m g} / \mathbf{L})\end{array}$ & $\begin{array}{c}\text { Suhu } \\
\left({ }^{\circ} \mathbf{C}\right)\end{array}$ & $\begin{array}{c}\text { Kadar oksigen } \\
\text { terlarut }(\mathbf{m g} / \mathbf{L})\end{array}$ & $\begin{array}{c}\text { Suhu } \\
\left({ }^{\circ} \mathbf{C}\right)\end{array}$ & $\begin{array}{c}\text { Kadar oksigen } \\
\text { terlarut }(\mathbf{m g} / \mathbf{L})\end{array}$ \\
\hline 0 & 14.62 & 14 & 10.31 & 28 & 7.83 \\
1 & 14.22 & 15 & 10.08 & 29 & 7.69 \\
2 & 13.83 & 16 & 9.87 & 30 & 7.56 \\
3 & 13.46 & 17 & 9.66 & 31 & 7.43 \\
4 & 13.11 & 18 & 9.47 & 32 & 7.30 \\
5 & 12.77 & 19 & 9.28 & 33 & 7.18 \\
6 & 12.45 & 20 & 9.09 & 34 & 7.06 \\
7 & 12.14 & 21 & 8.91 & 35 & 6.95 \\
8 & 11.84 & 22 & 8.74 & 36 & 6.84 \\
9 & 11.56 & 23 & 8.58 & 37 & 6.73 \\
10 & 11.29 & 24 & 8.42 & 38 & 6.62 \\
11 & 11.03 & 25 & 8.26 & 39 & 6.51 \\
12 & 10.78 & 26 & 8.11 & 40 & 6.41 \\
13 & 10.54 & 27 & 7.97 & & \\
\hline
\end{tabular}

Sumber : Cole dalam Efendi, 2003 
Tabel 4. Nilai tingkat pencemaran menurut WQI

\begin{tabular}{ccc}
\hline No & Nilai & Status Mutu Air \\
\hline 1 & $90-100$ & Sangat baik \\
2 & $70-90$ & Baik \\
3 & $50-70$ & Sedang \\
4 & $25-50$ & Buruk \\
5 & $0-25$ & Sangat buruk \\
\hline
\end{tabular}

Sumber : Bordalo et al. (2006)

5. Merubah satuan parameter yang belum seusai dengan satuan yang digunakan didalam WQI, membahas cara membaca tabel WQI, dan cara menggunakan aplikasi WQI.

A. Menghitung nilai change in temp (temperatur selisih antara nilai pengukuran 1 dan 2 , atau 2 dan 3 atau kalau banyak pengukurannya ambil rata-ratanya. (catatan waktu dan tempat harus sama)

Contoh: pengukuran $1=30^{\circ}$, pengukuran $2=$ $31^{\circ}$ jadi nilai yang diambil adalah $1^{\circ}$ (yang dimasukkan kedalam kolom WQI_Calculator)

$B$. Merubah satuan parameter

- Merubah satuan DO dari $\mathrm{mg} / \mathrm{L}$ menjadi $\%$ saturation dengan cara (Effendi, 2003):

$\%$ saturasi $=$ DO mg/L : DO Jenuh $\times 100 \%$ untuk mengetahui DO jenuh disajikan pada Tabel 3.

Contoh perhitungan \% saturasi disungai Kampar kanan dari hulu sampai hilir adalah sebagai berikut :

- Hulu:

Pada suhu $31^{\circ} \mathrm{C}$, kadar oksigen terlarut terukur adalah $5,16 \mathrm{mg} / \mathrm{L}$, sedangkan kadar oksigen secara teoritis adalah $7,43 \mathrm{mg} / \mathrm{L}$, maka persen saturasi adalah 5,16:7,43 x 100\% = $69 \%$ (tidak jenuh)
- Tengah:

Pada suhu $30^{\circ} \mathrm{C}$, kadar oksigen terlarut terukur adalah $4,34 \mathrm{mg} / \mathrm{L}$, sedangkan kadar oksigen secara teoritis adalah $7,56 \mathrm{mg} / \mathrm{L}$, maka persen saturasi adalah 4,34: 7,56 x 100\% = 57\% (tidak jenuh)

- Hilir

Pada suhu $28{ }^{\circ} \mathrm{C}$, kadar oksigen yang terukur adalah $6,86 \mathrm{mg} / \mathrm{L}$, sedangkan kadar oksigen secara teoritis adalah $7,83 \mathrm{mg} / \mathrm{L}$, maka persen saturasi adalah $6,86: 7,83 \times 100 \%=88 \%$ (tidak jenuh) (Effendi, 2003).

C. Menggunakan aplikasi WQI :

- Masuk ke alamat website : www.waterresearch.net

- Mengisi biodata di kolom-kolom yang tersedia di website

- Memasukkan nilai masing-masing parameter ke dalam kolom yang tersedia (nilai yang sudah dikonversi satuannya).

D. Hasil total dibandingkan dengan nilai tingkat pencemaran menurut WQI yang disajikan Tabel 4.

Sekilas tentang cara penggunaan WQI akan disajikan dalam Tabel 5 dan 6 .

Tabel 5. Hasil pengukuran eksitu dan insitu beberapa parameter

\begin{tabular}{ccccc}
\hline No & Parameter & hulu & $\begin{array}{c}\text { Stasiun } \\
\text { Tengah }\end{array}$ & Hilir \\
\hline 1 & & 7,98 & 6,24 & 4,73 \\
2 & $\mathrm{pH}$ (unit) & $69 \%$ & $57 \%$ & $88 \%$ \\
3 & DO (\%sat) & 12,6 & 30,6 & 337 \\
4 & Kekeruhan / Turbidity (NTU) & 0,501 & 0,46 & 0,636 \\
\hline
\end{tabular}

Kemudian nilai tersebut dimasukkan kedalam

Setelah itu masing-masing nilai total WQI yang WQI_Calculator yang teretra pada Tabel 6. Kemudian WQI_calculator akan menghitung secara otomatis didapat dibandingkan dengan nilai tingkat pencemaran WQI yang disajikan pada Tabel 7 . dan setelah itu akan muncul nilai total dari hasil penggabungan parameter yang diukur seperti yang disajikan pada Tabel 7. 
BTL Vol. 15 No. 1 Juni $2017:$ 5-9

Tabel 6. Water Quality Indeks_Calculator

\begin{tabular}{|c|c|c|c|c|c|c|}
\hline Parameter & $\left(\begin{array}{c}\text { TEST } \\
\underline{\text { RESULT }}\end{array}\right.$ & $\underline{\text { Units }}$ & $\frac{\text { Q- }}{\text { value }}$ & $\frac{\text { Weighting }}{\text { Factor }}$ & $\frac{\text { Weighting }}{\text { Factor }}$ & Subtotal \\
\hline$\underline{\mathrm{pH}}$ & & $\mathrm{pH}$ units & NM & $\underline{0.12}$ & $\underline{N M}$ & NM \\
\hline Change in temp & & degrees $\mathrm{C}$ & $\underline{N M}$ & $\underline{0.11}$ & $\underline{N M}$ & NM \\
\hline$\underline{\mathrm{DO}}$ & & $\frac{\%}{\text { saturation }}$ & $\underline{N M}$ & $\underline{0.18}$ & $\underline{N M}$ & $\underline{N M}$ \\
\hline BOD & & $\underline{\mathrm{mg} / \mathrm{L}}$ & NM & $\underline{0.12}$ & NM & NM \\
\hline Turbidity & & $\underline{\text { NTU }}$ & NM & $\underline{0.09}$ & $\underline{N M}$ & NM \\
\hline $\begin{array}{l}\text { Total } \\
\text { Phosphorus } \\
\end{array}$ & & $\mathrm{mg} / \mathrm{L} \mathrm{P}$ & $\underline{N M}$ & $\underline{0.11}$ & $\underline{N M}$ & $\underline{N M}$ \\
\hline Nitrate Nitrogen & & $\underline{\mathrm{mg} / \mathrm{L}}$ & $\underline{N M}$ & $\underline{0.10}$ & NM & $\underline{N M}$ \\
\hline E. coli* & & $\frac{\overline{\mathrm{CFU} / 100}}{\mathrm{~mL}}$ & NM & $\underline{0.17}$ & NM & NM \\
\hline $\begin{array}{l}\text { Fecal } \\
\text { Coliforms } \\
\end{array}$ & & $\frac{\mathrm{CFU} / 100}{\underline{\mathrm{mL}}}$ & NM & $\underline{0.17}$ & NM & NM \\
\hline & & & & \multicolumn{2}{|c|}{$\frac{\text { Water Quality Index }=}{\text { Water Quality Rating }=}$} & $\frac{0.00}{\frac{N M}{N M}}$ \\
\hline
\end{tabular}

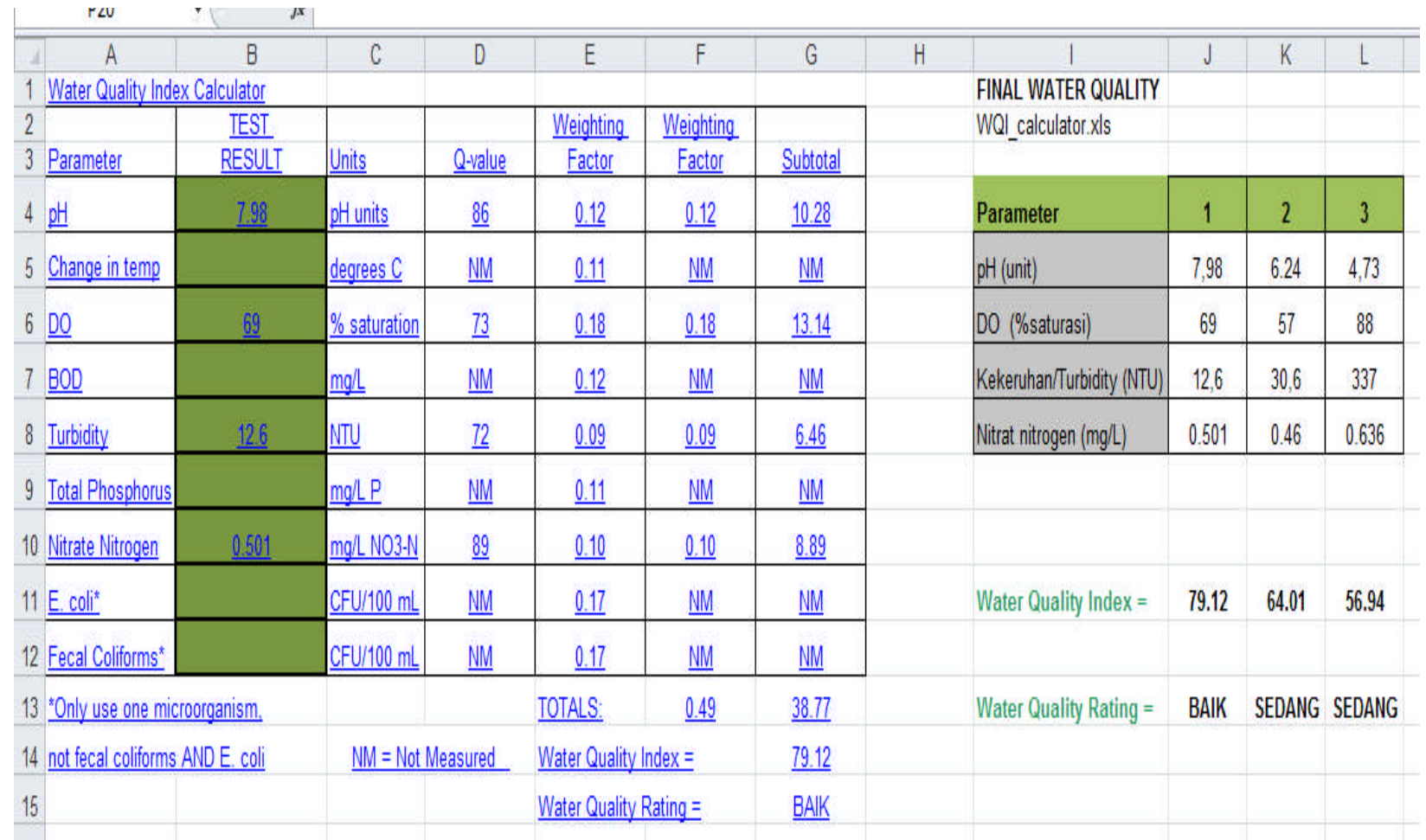

Gambar 2. Hasil pengukuran menggunakan metode WQI 
Tabel 7. Perbandingan nilai total WQI dengan Nilai tingkat pencemaran WQI

\begin{tabular}{|c|c|c|c|c|c|c|c|c|}
\hline$\overline{4}$ & A & B & C & D & $E$ & $\mathrm{~F}$ & G & $\mathrm{H}$ \\
\hline 20 & Nilai total WQI & & & & & Nilai Tingkat Pencemaran WQI & & \\
\hline \multicolumn{9}{|c|}{ 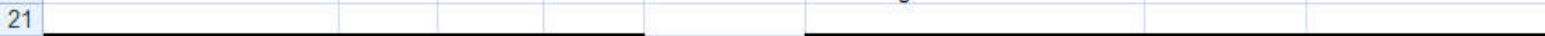 } \\
\hline 22 & Parameter & Hulu & Tengah & Hilir & & No & Nilai & Status Mutu Air \\
\hline 23 & $\mathrm{pH}$ (Unit) & 7.98 & 6.24 & 4.73 & & 1 & $90-100$ & Sangat baik \\
\hline 24 & DO (\%sat) & 69 & 57 & 88 & & 2 & $70-90$ & Baik \\
\hline 25 & Kekeruhan (NTU) & 12.6 & 30.6 & 337 & & 3 & $50-70$ & Sedang \\
\hline 26 & Nitrat $(\mathrm{mg} / \mathrm{L})$ & 0.501 & 0.45 & 0.636 & & 4 & $25-50$ & Buruk \\
\hline 27 & \multirow{3}{*}{ Nilai total WQI } & & & & & 5 & $0-25$ & Sangat buruk \\
\hline 28 & & 79.12 & 64.01 & 56.94 & & & & \\
\hline 29 & & & & & & & & \\
\hline 30 & \multirow[t]{2}{*}{ Nilai Tingkat pencemaran } & Baik & Sedang & Sedang & & & & \\
\hline 31 & & & & & & & & \\
\hline
\end{tabular}

\section{Hasil}

Analisis data dari 4 parameter ( $\mathrm{pH}, \mathrm{DO}$, Nitrat dan Kekeruhan) menggunakan WQI dari hulu sungai hingga hilir sungai menunjukkan adanya penurunan kualitas air. Nilai tersebut berbanding lurus dengan kondisi di lapangan, di mana di bagian tengah sungai sudah banyak aktifitas seperti perkebunan sawit, pertambangan pasir, KJA budidaya ikan, yang diduga sebagai pencemar utama selain kegiatan rumah tangga yang diduga sebagai sumber antrophogenik (bahan organik).

\section{KESIMPULAN}

Nilai WQI pada hulu sungai 79,12 pada hulu sungai, 64,01 pada tengah sungai dan 54,96 pada hilir sungai. Nilai tersebut menerangkan bahwa pada bagian hulu sungai berstatus baik, pada bagian tengah berstatus sedang dan pada bagian hilir sungai berstatus sedang menuju buruk.

\section{PERSANTUNAN}

Penelitian ini merupakan bagian dari kegiatan Ecological Assesment untuk Restocking Belida di Perairan Propinsi Riau. Penulis mengucapkan terima kasih kepada Bapak Dr. Joni Haryadi selaku kepala BPPKSDI dan Prof. Dr. Ir. H. Endi Setiadi Kartamihardja, selaku penanggung jawab kegiatan yang telah mengijinkan memakai data untuk penelitian, serta penulis mengucapkan terima kasih kepada semua pihak yang telah memberikan masukkan dan bimbingan sehingga terselesaikannya tulisan ini.

\section{DAFTAR PUSTAKA}

Alam. M., \& Pathak. J. K. (2010). Rapid assesment of water quality index of Ramnganga River Western Uttar Pradesh (India) using a computer programme. Nature and science .8 (11), 1-8

Anonimus. 2004. Himpunan Keputusan Kementerian Lingkungan Hidup Mengenai Pengelolaan Kualitas Air dan Pengendalian Pencemaran Air. Kementerian Lingkungan Hidup, Jakarta.

Anonimus. 2014. Kampar Dalam Angka2014.Badan Pusat Statistik Kabupaten Kampar. Riau

Azwir.2006. Analisa Pencemaran Air Sungai Tapung Kiri Oleh Limbah Industri Kelapa Sawit PT. Peputra Masterindo Di Kabupaten Kampar. Diakses pada tanggal 24 Oktober 2016

Bordalo. A. A, Teixeira R., dan Wiebe. W. J. 2006. A water quality index applied to an international shared river basin: the case of the Douro river. Environ Manage 38: 910-920

Effendi. H. 2003. Telaah Kualitas Air Bagi Alam Pengelolaan sumber Daya Dan Lingkungan Hidup. Hal-77,

Fithra. R. Y, dan Siregar. Y. I. 2010. Keanekaragaman Ikan Sungai Kampar Inventarisasi Dari Sungai Kampar Kanan. Diakses pada tanggal 24 Oktober 2016

Oram. B. monitoring-the-quality-of-surfacewaters. http://www.water-research.net/index.php/watertreatment/water-monitoring 